\title{
Epidemiology and treatment of mood disorder
in a day hospital setting from 1996 to 2007 : an Italian study
}

This article was published in the following Dove Press journal:

Neuropsychiatric Disease and Treatment

5 February 2013

Number of times this article has been viewed

\author{
Maria Luca' \\ Giuseppa Prossimo' \\ Vincenzo Messina' \\ Antonina Luca ${ }^{2}$ \\ Salvatore Romeo' \\ Carmela Calandra' \\ 'Department of Medical and \\ Surgery Specialties, Psychiatry \\ Unit, ${ }^{2}$ Department of \\ Neuroscience, University Hospital \\ Policlinico-Vittorio Emanuele, Catania, \\ Sicily, Italy
}

Background: The present study aimed: to assess prescribing patterns in the treatment of major depression, bipolar disorder type I, cyclothymia, and dysthymia from 1996 to 2007 in a day hospital setting; to evaluate the prevalence of the above-mentioned mood disorders and gender distribution; and to relate familiality, comorbidity, and marital status to each diagnosis.

Methods: Medical records for 777 day hospital patients with a diagnosis of major depression, bipolar disorder type I, cyclothymia, or dysthymia were grouped into two 6-year periods so as to compare the prescribing patterns of tricyclic antidepressants, selective serotonin reuptake inhibitors, noradrenergic reuptake inhibitors, serotonin and norepinephrine reuptake inhibitors, noradrenergic and specific serotonergic antidepressants, first-generation antipsychotics, secondgeneration antipsychotics, and mood stabilizers. Gender, prevalence, familiality, comorbidity, and marital status were related to each diagnosis.

Results: The most common mood disorder, with a female preponderance, was major depression, regardless of marital status. High percentages of familiality and comorbidity were found for major depression, while a reduction was found in the utilization of tricyclic antidepressants. There was no statistically significant difference in rates of prescription of selective serotonin reuptake inhibitors and noradrenergic reuptake inhibitors, but some irregularities were found upon evaluating each diagnosis (eg, increased utilization of these agents in dysthymia and major depression, respectively). There was an increase in prescriptions for serotonin and norepinephrine reuptake inhibitors, but no marked differences in utilization of noradrenergic and specific serotonergic antidepressants, which remained basically low. There was no significant difference in prescribing of first-generation antipsychotic agents, although a reduction was found. There was a significant increase in utilization of second-generation antipsychotics and mood stabilizers.

Conclusion: Our epidemiological findings are consistent with data reported in the literature regarding the high prevalence of major depression among the mood disorders, as well as the impact of familiality and comorbidity. Analysis of prescribing patterns for antidepressants, antipsychotics, and mood stabilizers in the treatment of mood disorders shows a shift from older to newer drugs, and wider use of mood stabilizers.

Keywords: antidepressants, antipsychotics, mood stabilizers, prescribing patterns, mood disorders, treatment

\section{Introduction}

The Diagnostic and Statistical Manual for Mental Disorders Fourth Edition, Text Revision (DSM-IV-TR) considers, each with its own specifications, major depression, dysthymia, bipolar disorder type I, bipolar disorder type II, and cyclothymia to be mood disorders. ${ }^{1}$ 
Generally speaking, mood disorders have a considerable impact on quality of life and social functioning. In a recent study assessing quality of life in patients with a mood disorder, in particular major depression, was related to poorer quality of life. Dysthymia and bipolar disorder have also been demonstrated to influence social relationships in a negative manner. ${ }^{2}$ At any rate, all mood disorders, whether in remission or not, affect various aspects of quality of life, including subjective well-being, life events, and likelihood of social support. ${ }^{3}$

Moreover, the occurrence of major depression in the general population is considerable, where it has a lifetime prevalence ranging from $10 \%$ to $15 \%,{ }^{4}$ with an increased rate in females. ${ }^{5}$ The lifetime prevalence of bipolar disorder type I is estimated at $0.6 \%$ and bipolar disorder type II at $0.4 \% .{ }^{6}$ However, recent evidence suggests that bipolar disorder in its broadest sense has a lifetime prevalence as high as $5 \% .{ }^{7}$ Bipolar disorder could also be interpreted as a chronic, progressive, multisystem disorder. ${ }^{8}$ On the other hand, even if dysthymia and cyclothymia are considered as "mild" mood disorders, it cannot be denied that they have considerable economic and social consequences. Further, while cyclothymia is relatively rare, dysthymia has a prevalence of $3 \%-6 \%{ }^{9}$

Due to the considerable clinical impact of mood disorders, careful attention is necessary when choosing an appropriate pharmacotherapy. The prescription of a specific drug (or multiple medications) depends not only on the severity of symptoms and risk of side effects, but also on many other variables. In particular, among all the factors that could influence the choice of prescription (personal experience, scientific evidence, influence of colleagues, economic considerations, drug marketing strategies), personal experience seems to be the most important, followed by scientific evidence. ${ }^{10}$

The advent of new pharmacological agents has increased the therapeutic possibilities in the management of mood disorders. Among these, the newer antidepressants, selective serotonin reuptake inhibitors (SSRIs) in particular, have had a rapid spread in medical practice in recent years, ${ }^{11-13}$ together with second-generation antipsychotics ${ }^{14,15}$ and mood stabilizers. ${ }^{16,17}$ In Italy, the 1990s saw diffusion of the second-generation antipsychotics and SSRIs into clinical practice, but it is still unknown if introduction of new drugs really modifies prescribing trends in the treatment of mood disorders. In order to answer this question, the primary aim of this study was to assess prescribing patterns (1996-2007) for tricyclic antidepressants, SSRIs, noradrenergic reuptake inhibitors (NaRIs), serotonin and norepinephrine reuptake inhibitors (SNRIs), noradrenergic and specific serotonergic antidepressants (NaSSAs), first-generation antipsychotics, second-generation antipsychotics, and mood stabilizers. In particular, major depression, bipolar disorder type I, cyclothymia, and dysthymia were considered. The secondary aim was to perform an epidemiological analysis of the sample in order to relate the prevalence of the illnesses being considered (along with gender distribution) and to relate familiality (occurrence of psychiatric illness among patient's relatives), comorbidity (two or more coexisting psychiatric disorders in the same patient, excluding the disorders under consideration) and marital status to every diagnosis.

\section{Materials and methods}

The medical records (January 1, 1996 to December 31, 2007) of 777 (313 male, 464 female) patients with a diagnosis of mood disorder (DSM-IV-TR criteria), who had been referred to the day hospital service of our Psychiatry Unit at the University Hospital Policlinico-Vittorio Emanuele, Catania, Italy, were selected from the hospital archives in order to extract the epidemiological and pharmacological data necessary for this study. Our day hospital service is dedicated to the treatment of all psychiatric illnesses on the request of a general practitioner. Once the service has been activated, the patient is entitled to one or multiple medical visits in the course of a year. However, for the collection of our data, only the first visit (to the day hospital service) was considered and, in the event of recurrent episodes of mood changes, only the episode that necessitated the first medical visit was taken into consideration. The period of time in question, ranging from January 1, 1996 to December 31,2007, was divided into two 6-year periods so as to perform a statistical comparison of prescribing patterns. The first 6-year period included 281 patients who had been admitted to our day hospital service from 1996 to 2001 (119 males, 162 females); the second 6-year period included 496 patients admitted from 2002 to 2007 (193 males, 303 females). We decided to analyze this period of time because, as stated above, from the 1990s onwards, there has been a steady increase in availability of new drugs in Italy. The mood disorders considered were major depression, bipolar disorder type I (manic/depressive/mixed episodes), cyclothymia, and dysthymia, due to the fact that the medical records reported only these disorders. The specific features of these disorders (eg, recurrence, severity of the illness) were not taken into consideration, along with bipolar disorder type II, given that diagnosis of this disorder was not represented in this study. Epidemiological data, as well as data regarding the drugs 
prescribed to the patients were collected in a database created ad hoc. A comparison of the prescribing patterns of the following pharmacological classes was carried out between the two 6-year periods: tricyclic antidepressants, SSRIs, NaRIs, SNRIs, NaSSAs, first-generation antipsychotics, second-generation antipsychotics, and mood stabilizers, including multiple drug therapies. Two comparisons were made between the prescribing patterns for both 6-year periods, ie, the percentage of use of single drugs and percentage of use of single drugs in the treatment of each of the illnesses considered. This study was approved by the local ethics committee. In addition, the gender and prevalence of the mood disorders under investigation were assessed. Moreover, familiality, comorbidity (Axis I-II of DSM-IV-TR, excluding the disorders considered), and marital status were related to each diagnosis.

\section{Statistical analysis}

The statistical analysis was performed using an Excel spreadsheet. The epidemiological investigation, the results of which are expressed in percentage form, was performed on the whole sample $(n=777)$. Analysis of prescribing patterns for the first 6-year period versus the second 6-year period was carried out utilizing Pearson's Chi-squared test on the percentage values, taking into consideration the percentage of use of single drugs and percentage of use of single drugs in the treatment of each of the illnesses considered. Values of $P \leq 0.05$ were considered to be statistically significant.

\section{Results}

\section{Prevalence and gender distribution}

Considering the whole sample, the most represented mood disorder was major depression (68.4\%), with a female preponderance ( $72.4 \%$ female versus $62.6 \%$ male). Tables 1 and 2 provide more details on diagnostic and gender distribution

Table I Diagnostic and gender distribution within the whole sample

\begin{tabular}{llll}
\hline Diagnosis & $\mathbf{n , ~ \%}$ & Male (n, \%) & Female (n, \%) \\
\hline $\begin{array}{l}\text { Major depression } \\
\text { Bipolar disorder } \\
\text { type I manic episode }\end{array}$ & $532(68.4 \%)$ & $196(62.6 \%)$ & $336(72.4 \%)$ \\
$\begin{array}{l}\text { Bipolar disorder } \\
\text { type I depressive }\end{array}$ & $50(6.5 \%)$ & $27(8.6 \%)$ & $23(5 \%)$ \\
$\begin{array}{l}\text { episode } \\
\text { Bipolar disorder }\end{array}$ & $3(0.4 \%)$ & $3(0.96 \%)$ & $0(0 \%)$ \\
$\begin{array}{l}\text { type I mixed episode } \\
\text { Dysthymia }\end{array}$ & $80(10.2 \%)$ & $26(8.3 \%)$ & $54(11.6 \%)$ \\
Cyclothymia & $8(1 \%)$ & $4(1.3 \%)$ & $4(0.9 \%)$ \\
\hline
\end{tabular}

Note: Diagnostic and gender distributions within the whole sample $(n=777)$ are reported as percentages.
Table 2 Gender differences within every diagnosis

\begin{tabular}{|c|c|c|}
\hline Diagnosis & Male (n, \%) & Female (n, \%) \\
\hline Major depression $(n=532)$ & $196(38.8 \%)$ & $336(63.2 \%)$ \\
\hline $\begin{array}{l}\text { Bipolar disorder type I } \\
\text { manic episode }(n=104)\end{array}$ & $57(54.8 \%)$ & $47(45.2 \%)$ \\
\hline $\begin{array}{l}\text { Bipolar disorder type I } \\
\text { depressive episode }(n=50)\end{array}$ & 27 (54\%) & $23(46 \%)$ \\
\hline $\begin{array}{l}\text { Bipolar disorder type I } \\
\text { mixed episode }(n=3)\end{array}$ & $3(100 \%)$ & $0(0 \%)$ \\
\hline Dysthymia $(\mathrm{n}=80)$ & $26(32.5 \%)$ & $54(67.5 \%)$ \\
\hline Cyclothymia $(\mathrm{n}=8)$ & $4(50 \%)$ & $4(50 \%)$ \\
\hline
\end{tabular}

Note: Gender differences within every diagnosis are reported in percentage.

according to diagnoses, while Table 3 shows the distribution of diagnoses within the two 6-year periods.

\section{Marital status}

A high prevalence of major depression was seen independent of marital status, followed by a high prevalence of manic and depressive bipolar disorder type I episodes in singles and divorced individuals, respectively. With regard to the other disorders considered, no remarkable data on marital status were obtained (see Table 4).

\section{Familiality and comorbidity}

A high percentage of positive familiality (65.8\%) and DSMIV-TR Axis I-II comorbidity (68.4\%) was found in patients suffering from major depression (Figures 1 and 2).

\section{Prescribing patterns: first versus second 6-year period}

The following are the results regarding the prescribing patterns of the drugs evaluated in general and according to diagnosis.

\section{Tricyclic antidepressants}

A statistically significant reduction in utilization of tricyclic antidepressants was found by comparing the two 6-year

Table 3 Diagnostic distributions of the first ( $1996-200 \mathrm{I} ; \mathrm{n}=28 \mathrm{I})$ and second 6-year periods (2002-2007; $n=496)$

\begin{tabular}{|c|c|c|}
\hline Diagnosis & $\begin{array}{l}\text { First 6-year } \\
\text { period }(n, \%)\end{array}$ & $\begin{array}{l}\text { Second 6-year } \\
\text { period }(n, \%)\end{array}$ \\
\hline Major depression & 177 (63\%) & 355 (71.6\%) \\
\hline $\begin{array}{l}\text { Bipolar disorder type I } \\
\text { manic episode }\end{array}$ & 24 (8.5\%) & $82(16.6 \%)$ \\
\hline $\begin{array}{l}\text { Bipolar disorder type I } \\
\text { depressive episode }\end{array}$ & $21(7.5 \%)$ & $29(5.8 \%)$ \\
\hline $\begin{array}{l}\text { Bipolar disorder type I } \\
\text { mixed episode }\end{array}$ & I (0.3\%) & $2(0.4 \%)$ \\
\hline Dysthymia & $57(20 \%)$ & $23(4.63 \%)$ \\
\hline Cyclothymia & I (0.3\%) & $5(1 \%)$ \\
\hline
\end{tabular}


Table 4 Marital status according to diagnosis

\begin{tabular}{|c|c|c|c|c|}
\hline Diagnosis & $\begin{array}{l}\text { Single } \\
n=|5|(n, \%)\end{array}$ & $\begin{array}{l}\text { Married } \\
n=447(n, \%)\end{array}$ & $\begin{array}{l}\text { Divorced } \\
n=30(n, \%)\end{array}$ & $\begin{array}{l}\text { Widowed } \\
n=4 I(n, \%)\end{array}$ \\
\hline Major depression & 81 (53.6\%) & $318(71.1 \%)$ & 17 (56.7\%) & 32 (78.1\%) \\
\hline Bipolar disorder type I manic episode & $38(25.4 \%)$ & $47(10.5 \%)$ & $4(13.3 \%)$ & $3(7.3 \%)$ \\
\hline Bipolar disorder type I depressive episode & $13(8.7 \%)$ & $24(5.4 \%)$ & $6(20 \%)$ & $2(4.9 \%)$ \\
\hline Bipolar disorder type I mixed episode & $0(0 \%)$ & $3(0.7 \%)$ & $0(0 \%)$ & $0(0 \%)$ \\
\hline Dysthymia & $16(10.7 \%)$ & 51 ( $11.4 \%)$ & $3(10 \%)$ & $4(9.8 \%)$ \\
\hline Cyclothymia & $3(2 \%)$ & $4(0.9 \%)$ & $0(0 \%)$ & $0(0 \%)$ \\
\hline
\end{tabular}

periods $\left(\chi^{2}=7.53 ; P=0.006\right)$. In particular, utilization of these agents decreased from $18 \%$ to $3 \%$ in major depression $\left(\chi^{2}=10.9 ; P=0.0009\right)$, from $14.2 \%$ to $0 \%$ in depressive bipolar disorder type I episodes $\left(\chi^{2}=7.93 ; P=0.004\right)$, from $19.2 \%$ to $17.3 \%$ in dysthymia $\left(\chi^{2}=5.24 ; P=0.02\right)$, from $100 \%$ to $0 \%$ in cyclothymia (episodes of mood deterioration, $\left.\chi^{2}=77.69 ; P=1.21 \mathrm{E}-18\right)$.

\section{SSRIs}

When comparing the two 6-year periods, there was no statistically significant difference in rates of prescription of this pharmacological class $\left(\chi^{2}=0.61 ; P=0.43\right)$. However, when considering each diagnosis, significantly increased utilization of SSRIs was found in the treatment of dysthymia ( $42.1 \%$ versus $60.8 \% ; \chi^{2}=12.92 ; P=0.0003$ ).

\section{$\mathrm{NaRls}$}

Comparing the two 6-year periods, there was no statistically significant difference in the prescription of NaRIs $\left(\chi^{2}=0.39\right.$; $P=0.52)$. However, some peculiarities were found on evaluating according to diagnosis, in that their utilization increased from $0 \%$ to $100 \%$ in the treatment of major depression $\left(\chi^{2}=42.98 ; P=5.52 \mathrm{E}-11\right)$, and from $0 \%$ to $4.3 \%$ in the treatment of dysthymia. In contrast, their utilization in cyclothymia (depressive episodes) decreased from $100 \%$ to $0 \%\left(\chi^{2}=77.69 ; P=1.21 \mathrm{E}-18\right)$.

\section{SNRIs}

There was an increase in utilization of SNRIs from the first to the second 6-year period $\left(\chi^{2}=8.01 ; P=0.004\right)$. In particular, prescription of these agents increased from $6.2 \%$ to $19.7 \%$ in major depression $\left(\chi^{2}=4.62 ; P=0.03\right)$, and from $5.2 \%$ to $17.3 \%$ in dysthymia $\left(\chi^{2}=15.94 ; P=6.5 \mathrm{E}-05\right)$, and decreased from $100 \%$ to $0 \%$ in cyclothymia $\left(\chi^{2}=77.69\right.$; $P=1.21 \mathrm{E}-18)$.

\section{NaSSAs}

Comparing the two 6-year periods, prescriptions for NaSSAs did not show a statistically significant difference $\left(\chi^{2}=0.0005 ; P=0.98\right)$. Cyclothymia showed a reduction from $100 \%$ to $0 \%\left(\chi^{2}=77.69 ; P=1.21 \mathrm{E}-18\right)$.

See Figure 3 for more details on prescribing patterns for antidepressants (first versus second 6-year period).

\section{First-generation antipsychotics}

There was no statistically significant difference in prescribing for the first-generation antipsychotics comparing the two 6-year periods $\left(\chi^{2}=2.27 ; P=0.13\right)$. On the other hand, a reduction from $23.1 \%$ to $8.4 \%$ was found in treatment of the psychotic features of major depression $\left(\chi^{2}=7.13 ; P=0.007\right)$, from $58.3 \%$ to $34.1 \%$ in bipolar disorder type I (manic episodes, $\chi^{2}=6.81$; $P=0.009$ ) and from $100 \%$ to $0 \%$ in cyclothymia (elevated mood episodes, $\left.\chi^{2}=77.69 ; P=1.21 \mathrm{E}-18\right)$.

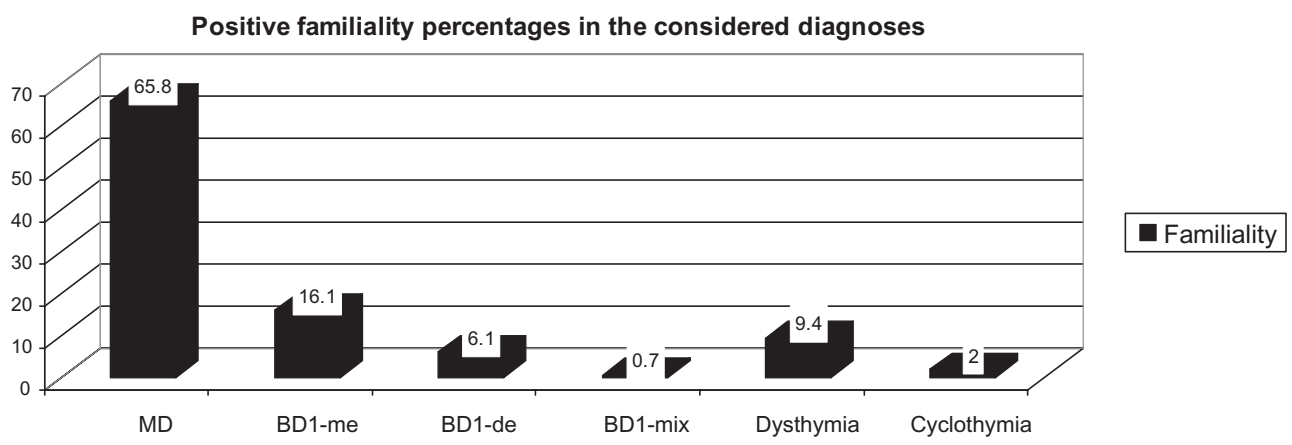

Figure I The percentages of positive familiality within every diagnosis are reported in percentage.

Abbreviations: MD, Major depression; BDI-me, Bipolar Disorder type I manic episode; BDI-de, Bipolar Disorder type I depressive episode; BDI-mix, Bipolar Disorder type I mixed episode. 
Positive comorbidity percentages in the considered diagnoses

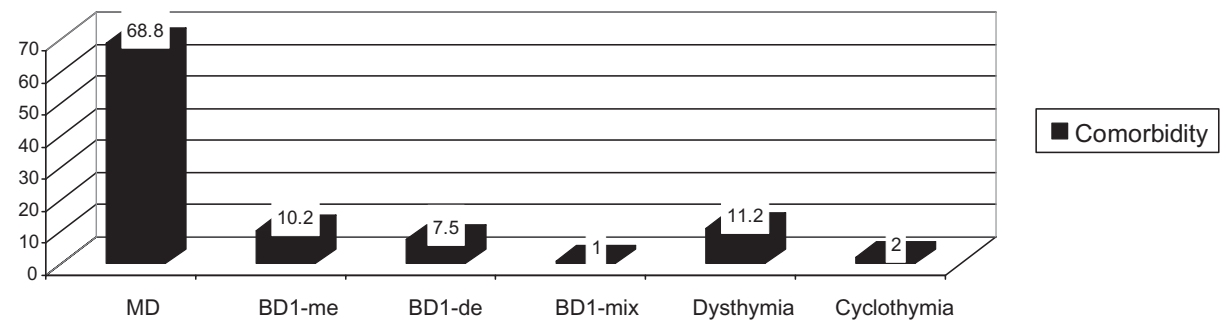

Figure 2 The percentages of positive comorbidity within every diagnosis are reported in percentage.

Abbreviations: MD, Major depression; BDI-me, Bipolar Disorder type I manic episode; BDI-de, Bipolar Disorder type I depressive episode; BDI-mix, Bipolar Disorder type I mixed episode.

\section{Second-generation antipsychotics}

There was a statistically significant difference in utilization of second-generation antipsychotics between the first and second 6-year period $\left(\chi^{2}=3.77 ; P=0.05\right)$. In particular, their prescription increased from $8.3 \%$ to $34.1 \%$ in bipolar disorder type I (manic episodes, $\chi^{2}=5.81 ; P=0.01$ ), and from $0 \%$ to $100 \%$ in bipolar disorder type I (mixed episodes, $\chi^{2}=42.98$; $P=5.52 \mathrm{E}-11)$. However, their utilization decreased from $100 \%$ to $20 \%$ in cyclothymia (mood elevation, $\chi^{2}=3.26 ; P=0.07$ ).

\section{Mood stabilizers}

There was a statistically significant increase in prescriptions for mood stabilizers when comparing the two 6-year periods $\left(\chi^{2}=6.49 ; P=0.01\right)$. In particular, their utilization increased from $0 \%$ to $100 \%$ in bipolar disorder type I (mixed episodes, $\left.\chi^{2}=42.98 ; P=5.52 \mathrm{E}-11\right)$ and from $7 \%$ to $26 \%$ in dysthymia $\left(\chi^{2}=20.42 ; P=6.19 \mathrm{E}-06\right)$.

\section{Discussion}

Epidemiological analysis of the whole sample showed a high prevalence of major depression, with a female preponderance.
It is well known that, among the mood disorders, major depression has a very high incidence, being encountered in one in every $10-20$ patients in the primary care setting, ${ }^{18}$ with a female preponderance. ${ }^{5}$ Taking into account the impact of major depression in the general population, the higher incidence of depression in women highlights the need for special attention in terms of prevention and social support, especially in important life events, such as puberty, pregnancy, and menopause. The health system should offer services (from general medicine to the specialties) with many professionals able to cope with women's various psychosocial needs. In this study, the highest percentage of comorbidity was found in patients suffering from major depression. Indeed, researchers have reported the occurrence of DSM-IV-TR Axis I-II comorbidities in this disorder. ${ }^{19,20}$ The presence of a comorbid disorder can have a negative influence on the functioning of patients who are depressed, on the course of the illness, on recurrence, and even on the risk of relapse. ${ }^{20}$ It is also known that familiality plays an important role in mood disorders. ${ }^{21,22}$ Our analysis showed a high percentage of familiality in major depression. The literature reports that

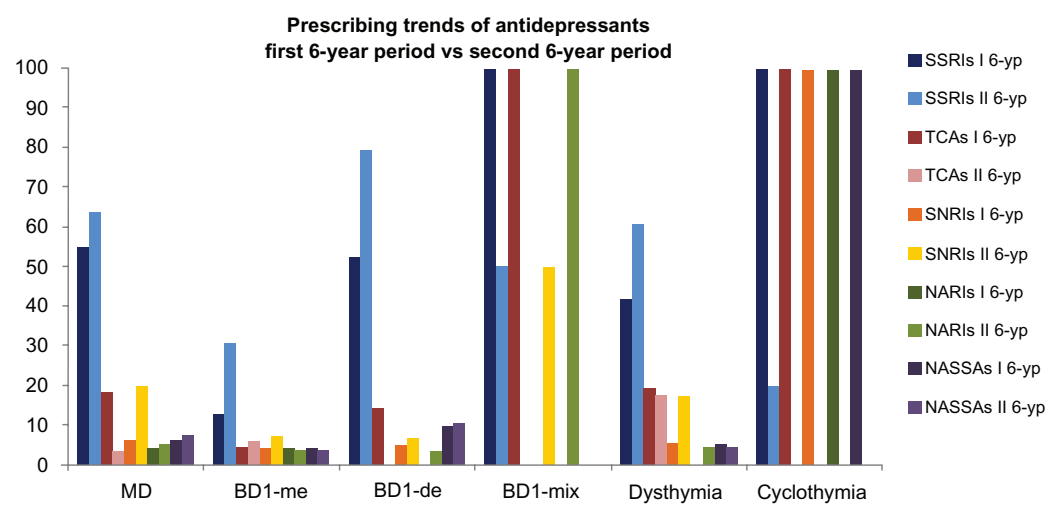

Figure 3 The differences in the prescribing patterns (first 6-year period [I 6-yp] versus second 6-year period [II 6-yp]) are presented, referring to the following antidepressants: selective serotonine reuptake inhibitors (SSRIs), tricyclic antidepressants (TCAs), serotonine and norepinephrine reuptake inhibitors (SNRIs), noradrenergic reuptake inhibitors (NaRIs), noradrenergic and specific serotonergic antidepressants (NaSSAs).

Abbreviations: MD, Major depression; BDI-me, Bipolar Disorder type I manic episode; BDI-de, Bipolar Disorder type I depressive episode; BDI-mix, Bipolar Disorder type I mixed episode. 
familiality in particular is related to severe, recurrent, and early-onset depression. ${ }^{22}$ In fact, the subtype with the strongest heritable component seems to be early-onset recurrent depression. ${ }^{23}$ In addition, in our sample, a high prevalence of major depression was found independent of marital status, followed by a high prevalence of manic and depressive bipolar disorder type I episodes in singles and divorced persons, respectively. These data confirm the well-known impact of "being alone" on mental health and, conversely, the adverse effects that mental disorders have on life. ${ }^{24-26}$

With regards to pharmacoepidemiology, some studies have described the widespread use of antidepressants, antipsychotics, and mood stabilizers in clinical practice and the changes in their prescribing patterns during recent years. ${ }^{11-17}$ In accordance with the literature, our analysis of the prescribing patterns of antidepressants, antipsychotics, and mood stabilizers in mood disorders showed a shift from old to newer drugs, ${ }^{27,28}$ and wider utilization of mood stabilizers. As expected, with SNRIs being relatively new, a statistically significant increase in their utilization was seen; in contrast, there was a reduction in prescription of tricyclic antidepressants when the two 6-year periods were compared. Despite the clinical efficacy of these drugs, their demonstrated toxicity ${ }^{29}$ may have limited their utilization. As with the other antidepressant classes evaluated, no statistically significant differences in global prescriptions were found, but some patterns were identified when their utilization in specific diagnoses was considered. Although there was no statistically significant difference in prescription of SSRIs, utilization of these agents remained high, with increased use in the treatment of dysthymia, which could be due to their tolerability, ${ }^{30}$ making them safer for longer term use. Prescription of NaRIs in particular for treatment of major depression showed a small increase, which is probably due to the fact that their efficacy is still controversial. ${ }^{31}$ On the other hand, when considering certain diagnoses, it must be said that these data are difficult to interpret due to the small sample of this study. Utilization of NaSSAs, which remained basically low probably because of their tendency to cause weight gain and drowsiness, ${ }^{32}$ did not change significantly between the two 6-year periods. Taking into consideration the prescription of antipsychotics, as expected, utilization of firstgeneration antipsychotics decreased, having been replaced by second-generation antipsychotics. This finding is consistent with the literature, ${ }^{27,28}$ which reports a huge increase in prescription of second-generation antipsychotics. It is easy to trace these data to the better perceived safety profile of this pharmacological class, even though the safety profiles of second-generation antipsychotics differ considerably, and serious adverse effects have been demonstrated. ${ }^{33}$ Finally, there was a considerable increase in prescription of mood stabilizers when comparing the two 6-year periods. In particular, it is interesting to note the increased use of this medication in dysthymia and mixed episodes in bipolar disorder I. Our hypothesis is that the choice of such a therapy may well depend on the demonstrated protective effects of mood stabilizers against suicidal behavior. ${ }^{34}$

In the light of these results, one can understand how the pharmacological approach to treatment of mood disorders has changed so significantly. In 1995, 40.6\% of patients with bipolar disorder were prescribed at least two psychotropic medications. By 2009, this proportion had increased to $78.5 \%{ }^{27}$ Indeed, even the use of polypharmacy had increased. Complex polypharmacy, involving at least four medications, occurs in approximately one in five individuals with bipolar disorder, ${ }^{35}$ considering also that some antipsychotics, such as quetiapine, show efficacy for mood stabilization. ${ }^{36}$ The choice of a polypharmacological approach is frequent in the case of refractory bipolar disorder or unipolar depression. ${ }^{37}$ The recent availability on the market of even newer drugs, such as agomelatine, as well as the new therapeutic options that could come about as a result of advances in biological psychiatry, may lead to another revolution in the treatment of mood disorders.

To the best of our knowledge, this is the first Italian study evaluating the prescribing patterns of all pharmacological classes in the treatment of mood disorders. However, it has some limitations, in that the sample sizes for certain diagnoses were very small; in these cases, the proportions of drug prescriptions showed huge differences due to changes within a small sample, considering also the cases of multiple drug therapy. The number of patients in the second 6-year period was greater than that in the first 6-year period. This could reflect changes in Italian health policy, which determined a preference for admission to the day hospital service rather than inpatient hospitalization. Due to the observational nature of this study, we do not know the evolution of the disorders studied (eg, patients visiting during a depressive episode may have presented subsequently with a manic episode). Bipolar disorder type II was not considered in our study because no patient with this diagnosis was admitted to our day hospital service during the study period, whereas cyclothymia was taken into consideration. This may be because of misdiagnosis, in that some of the patients with 
a diagnosis of cyclothymia or depression should have had a diagnosis of bipolar disorder type II. However, we were not able to confirm such a hypothesis. In addition, we do not have any data about the reasons leading to individual treatment decisions. More research is necessary in order to confirm or disprove our findings. In conclusion, the impact of mood disorders should not be underestimated. Despite the availability of a variety of treatment options, mood disorders remain a challenging field for clinicians, whose task is to find a person-centered treatment when treating these complex disorders.

\section{Disclosure}

The authors report no conflicts of interest in this work.

\section{References}

1. American Psychiatric Association. Diagnostic and Statistical Manual of Mental Disorders Text Revision (DSM-IV-TR), 4th ed. Washington, DC: American Psychiatric Association; 2002.

2. Guan B, Deng Y, Cohen P, Chen H. Relative impact of Axis I mental disorders on quality of life among adults in the community. $J$ Affect Disord. 2011;131:293-298.

3. Cramer V, Torgersen S, Kringlen E. Mood disorders and quality of life. A community study. Nord J Psychiatry. 2010;64:58-62.

4. Lépine JP, Briley M. The increasing burden of depression. Neuropsychiatr Dis Treat. 2011;7 Suppl 1:3-7.

5. Kuehner C. Gender differences in unipolar depression: an update of epidemiological findings and possible explanations. Acta Psychiatr Scand. 2003;108:163-174.

6. Merikangas KR, Jin R, He JP, et al. Prevalence and correlates of bipolar spectrum disorder in the world mental health survey initiative. Arch Gen Psychiatry. 2011;68:241-251.

7. Akiskal HS, Bourgeois ML, Angst J, Post R, Möller H, Hirschfeld R. Re-evaluating the prevalence of and diagnostic composition within the broad clinical spectrum of bipolar disorders. J Affect Disord. 2000; 59 Suppl 1:5-30.

8. Leboyer M, Kupfer DJ. Bipolar disorder: new perspectives in health care and prevention. J Clin Psychiatry. 2010;71:1689-1695.

9. Brieger P, Marneros A. [Dysthymia and cyclothymia - serious consequences of rarely diagnosed disorders.] Versicherungsmedizin. 1998;50:215-218. [German.]

10. Dickson-Mulinga J. Rationale behind psychiatrists' choice of drug. Psychiatrist. 1998;22:677-680.

11. Pirraglia PA, Stafford RS, Singer DE. Trends in prescribing of selective serotonin reuptake inhibitors and other newer antidepressant agents in adult primary care. Prim Care Companion J Clin Psychiatry. 2003;5: $153-157$.

12. Bramness JG, Hausken AM, Sakshaug S, Skurtveit S, Rønning M. [Prescription of selective serotonin reuptake inhibitors 1990-2004.] Tidsskr Nor Laegeforen. 2005;125:2470-2473. [Norwegian.]

13. Bauer M, Monz BU, Montejo AL, et al. Prescribing patterns of antidepressants in Europe: results from the Factors Influencing Depression Endpoints Research (FINDER) study. Eur Psychiatry. 2008;23: 66-73.

14. Bret P, Bret MC, Queuille E. [Prescribing patterns of antipsychotics in 13 French psychiatric hospitals.] Encephale. 2009;35:129-138. [French.]

15. Yang M, Barner JC, Lawson KA, et al. Antipsychotic medication utilization trends among Texas veterans: 1997-2002. Ann Pharmacother. 2008;42:1229-1238.
16. Citrome L. Use of lithium, carbamazepine, and valproic acid in a state-operated psychiatric hospital. J Pharm Technol. 1995;11:55-59.

17. Altamura AC, Lietti L, Dobrea C, Benatti B, Arici C, Dell'Osso B. Mood stabilizers for patients with bipolar disorder: the state of the art. Expert Rev Neurother. 2011;11:85-99.

18. Halaris A. A primary care focus on the diagnosis and treatment of major depressive disorder in adults. J Psychiatr Pract. 2011;17:340-350.

19. Corruble E, Ginestet D. [Comorbidity in a sample of hospitalized depressed patients.] Encephale. 1996;22:119-126. [French.]

20. Luca M, Luca A, Calandra C. Borderline personality disorder and depression: an update. Psychiatr Q. 2011;83:281-292.

21. Hua LL, Wilens TE, Martelon M, Wong P, Wozniak J, Biederman J. Psychosocial functioning, familiality, and psychiatric comorbidity in bipolar youth with and without psychotic features. J Clin Psychiatry. 2011;72:397-405.

22. Janzing JG, de Graaf R, ten Have M, Vollebergh WA, Verhagen M, Buitelaar JK. Familiality of depression in the community; associations with gender and phenotype of major depressive disorder. Soc Psychiatry Psychiatr Epidemiol. 2009;44:1067-1074.

23. Levinson DF, Zubenko GS, Crowe RR, et al. Genetics of recurrent early-onset depression (GenRED): design and preliminary clinical characteristics of a repository sample for genetic linkage studies. $\mathrm{Am}$ J Med Genet B Neuropsychiatr Genet. 2003;119B:118-130.

24. Gibb SJ, Fergusson DM, Horwood LJ. Relationship separation and mental health problems: findings from a 30-year longitudinal study. Aust N Z J Psychiatry. 2011;45:163-169.

25. Lieberman DZ, Massey SH, Goodwin FK. The role of gender in single vs married individuals with bipolar disorder. Compr Psychiatry. 2010;51:380-385.

26. Breslau J, Miller E, Jin R, et al. A multinational study of mental disorders, marriage, and divorce. Acta Psychiatr Scand. 2011;124:474-486.

27. Hayes J, Prah P, Nazareth I, et al. Prescribing trends in bipolar disorder: cohort study in the United Kingdom THIN primary care database 1995-2009. PLoS One. 2011;6:e28725.

28. Hollingworth SA, Siskind DJ, Nissen LM, Robinson M, Hall WD. Patterns of antipsychotic medication use in Australia 2002-2007. Aust N Z J Psychiatry. 2010;44:372-377.

29. Jefferson JW. A review of the cardiovascular effects and toxicity of tricyclic antidepressants. Psychosom Med. 1975;37:160-179.

30. Draper B, Berman K. Tolerability of selective serotonin reuptake inhibitors: issues relevant to the elderly. Drugs Aging. 2008;25:501-519.

31. Eyding D, Lelgemann M, Grouven U, et al. Reboxetine for acute treatment of major depression: systematic review and meta-analysis of published and unpublished placebo and selective serotonin reuptake inhibitor controlled trials. BMJ. 2010;341:c4737.

32. Watanabe N, Omori IM, Nakagawa A, et al. Safety reporting and adverse-event profile of mirtazapine described in randomized controlled trials in comparison with other classes of antidepressants in the acute-phase treatment of adults with depression: systematic review and meta-analysis. CNS Drugs. 2010;24:35-53.

33. Yurkov V, Jha S, Collins D, Alessi-Severini S. Second-generation antipsychotic agents: a review of safety profiles. Curr Psychiatry Rev. 2012;8:49-68.

34. Yerevanian BI, Koek RJ, Mintz J. Lithium, anticonvulsants and suicidal behavior in bipolar disorder. J Affect Disord. 2003;73:223-228.

35. Goldberg JF, Brooks JO 3rd, Kurita K, et al. Depressive illness burden associated with complex polypharmacy in patients with bipolar disorder: findings from the STEP-BD. J Clin Psychiatry. 2009;70: $155-162$.

36. Altamura AC, Mundo E, Dell'Osso B, Tacchini G, Buoli M, Calabrese JR. Quetiapine and classical mood stabilizers in the longterm treatment of bipolar disorder: a 4-year follow-up naturalistic study. J Affect Disord. 2008;110:135-141.

37. Frye MA, Ketter TA, Leverich GS, et al. The increasing use of polypharmacotherapy for refractory mood disorders: 22 years of study. J Clin Psychiatry. 2000;61:9-15. 


\section{Publish your work in this journal}

Neuropsychiatric Disease and Treatment is an international, peerreviewed journal of clinical therapeutics and pharmacology focusing on concise rapid reporting of clinical or pre-clinical studies on a range of neuropsychiatric and neurological disorders. This journal is indexed on PubMed Central, the 'PsycINFO' database and CAS.

The manuscript management system is completely online and includes a very quick and fair peer-review system, which is all easy to use. Visit http://www.dovepress.com/testimonials.php to read real quotes from published authors.

\footnotetext{
Submit your manuscript here: http://www.dovepress.com/neuropsychiatric-disease-and-treatment-journal
} 